\title{
CRISIS SOBERANA: ANTESALA A UNA NUEVA CRISIS GLOBAL
}

SOVEREIGN CRISIS: PRELUDE TO A NEW GLOBAL CRISIS

\section{Nicko Alberto Gomero Gonzales * Eduardo Alberto Montes Farro**}

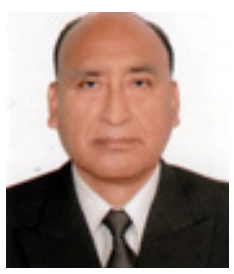

Docentes Asociados de la Facultad de Ciencias Contables - UNMSM

[Recepción: Agosto de 2011/ Conformidad: Octubre de 2011]

\section{RESUMEN}

Una nueva crisis se avecina, y quizás sea con mayor fuerza a lo experimentando en el 2008, que como bien se conoce creo escenarios de pánicos en las bolsas globales y retrocesos en el sector real de la economía, cuyos efectos aún permanecen latentes en muchas economías del Euro y también Norteamérica. La crisis ahora emanan de los desequilibrios fiscales, especialmente de aquellos países que no han sabido administrar con inteligencia sus cuentas fiscales, producto de ello, algunos ya se encuentran ad porta de la insolvencia económica, tal como lo es Grecia en la Zona del Euro. En este mismo camino se encuentran otras economías como Italia y porque no decir también EE.UU. países que han sido castigados con menores calificaciones para sus cumplimientos crediticos. estos resultados, dada la globalización de los mercados no se quedan allí sino que se reproducen sistemáticamente a otras espacios económicas como son las Américas, entre ellos el Perú, ya que ningún tipo de economía podría argumentar que se puede sentir inmune cuando se presentan crisis de este tipo, llamada crisis soberana. De agravarse esta crisis de deuda pública, los efectos serán altamente pernicioso para las economías, por ello amerita que los gobiernos rediseñen sus políticas públicas globales a fin de mantener sus cuentas fiscales y económicas en total estabilidad.

Palabras claves: crisis soberana, PBI global, déficit fiscal. Deuda pública, bonos soberanos.

\begin{abstract}
A new crisis is looming, and perhaps more strongly to the experience in 2008, which as is well known scenes of panic believe in global stock markets and declines in the real sector of the economy, the effects remain latent in many economies Euro and North America. The crisis now emanating from the fiscal imbalances, especially those countries that have failed to intelligently manage their fiscal accounts as a result of this, some are already on the verge of insolvency, as is Greece in the Euro Zone. In the same way there are other economies such as Italy and why not also say U.S. countries that have been punished with lower grades for their compliance credits. these results, given the globalization of markets will not stay there but that play consistently to other economic areas such as the Americas, including Peru, as no kind of economy could argue that you can be immune when crises occur this type, called a sovereign crisis. To worsen the debt crisis, the effects will be highly detrimental to the economy, so governments warrants redesign their global public policy to keep its fiscal accounts and total economic stability.
\end{abstract}

Keywords: sovereign crisis, global GDP, fiscal deficit. Public debt bonds.

* Doctor en Ciencias Económicas, Docente Investigador de la Facultad de Ciencias Contables - UNMSM. Docente de la Unidad de Postgrado - UNMSM. E- mail: nickgo_6@msn.com, gomero_econ@yahoo.es

** Egresado de Maestría en contabilidad con mención en costos y presupuestos en la gestión estratégica -UNMSM. Contador Público Colegiado Certificado. Docente Investigador de la Facultad de Ciencias Contables, UNMSM.

E- mail: amontesfa@yahoo.es 


\section{INTRODUCCION}

El mundo global está experimentando una nueva crisis. Ahora ya no se habla de la crisis hipotecaria, tampoco de bancos en insolvencia, como lo fue el Lheman Brother, sino hora la atención está en los gobiernos, específicamente los llamados del primer mundo, que no han sabido manejar adecuadamente sus cuentas fiscales. Estas economías están entrando a escenarios peligrosos de incumplimientos de pagos de deudas contraídas, de allí el nombre de crisis soberana, situación que los ha llevado a ser calificados como de alto riesgo.

La espiral de crisis no se detiene, los países de las Zona del Euro están agravando sus panorama macroeconómico, EE:UU sigue la misma tendencia, solo quedan dos espacios que aun la crisis no ha remecido con gran fuerza, como son las Américas y los países asiáticos, bien llamados Emergentes. Estos resultados reflejan simplemente las inteligentes políticas publicas que se viene ensayando, donde se ha puesto en primera línea la sostenibilidad del equilibrio de las cuentas fiscales.

Es cierto que, de agravarse la crisis soberana global, todas las economías sufrirán el impacto una más que otras, entre ellas está el Perú, que como bien se conoce esta anclada a los vaivenes de la economía internacional, ya que es un país que sustenta sus resultados fiscales y macroeconómicos en general en las exportaciones de productos primarios o tradicionales, los cuales ahora están dirigidos en mayor grado a la economía asiática.

Este grado de eslabonamiento global amerita el desarrollo del presente artículo científico, ya que así se podrá evidenciar que la economía nacional, a pesar de los excelentes fundamentos económicos, también podría ser afectado por esta crisis soberana de tipo global.

\section{CRISIS FINANCIERA}

La nueva crisis, cuyos efectos se viene enraizando en las principales economías del mundo, se ha incubado en las cuentas fiscales de los gobiernos. A diferencias de la primera oleada financiera, cuyo punto de partida fue el desplome del mercado hipotecario en Norteamérica, la actual situación económica y financiera global obedece a los desequilibrios de las cuentas fiscales, en especial en aquellos países que no supieron manejar con prudencia sus cuentas presupuestales. Como se dice en economía "no existe lonche gratis”, por ello, bajo este principio filosófico, los países que vivieron una algarabía financiera sin prever el futuro, tendrán que asumir responsabilidades, más allá de solamente de sanear sus cuentas internas, sino que deben ensayar medidas para aplacar las turbulencias de los mercados reales y financieros globales.

Cuando se desatan dos crisis económicas en menos de 5 años, los efectos directos y colaterales pueden ser más nocivos de los esperados, su grado de impacto puede ser tan fuerte que bien podría comprometer hasta sistemas de gobiernos, dando paso a modelos que se supusieron olvidados por el mundo occidental. Esta nueva posición política o geopolítica podría darse bajo el pretexto de una supuesta inviabilidad del modelo de mercado, no cabe duda que, el alejamiento de las políticas económicas y publicas, de esta última doctrina económica podría ser un grave peligro para la sostenibilidad del modelo de globalización, que si bien ha generado graves asimetrías sociales y económicas, pero a la vez ha creado importantes espacios para la inclusión de las economías emergentes dentro de la senda de crecimiento. Uno de esos casos es Perú, Brasil en Latinoamérica, países que se han convertido en escenarios importantes para las inversiones extranjeras 
Hay que tener presente que, cuando se habla de inclusión no solo hay que pensar en la introducción de las clases sociales menos favorecidas dentro de la corriente de la modernidad, si no que este término es mucho más que un simple concepto social, ya que también involucra aquellas economías, que por años no pudieron entrar a los escenarios de la prosperidad económica global y que ahora gracias a políticas públicas inteligentes y a una férrea disciplina fiscal están desarrollando fortalezas que solo eran de exclusividad de las economías avanzadas o del primer mundo, uno de los ejemplos más claros es china, que amenaza en quitarle la hegemonía económica a EE.UU. Es conveniente precisar que un gobierno serio y responsable no debe ensayar medidas para satisfacer intereses de grupos de poder o saldar cuentas con beneficios particulares, lo contrario, los nuevos retos globales exige que los gobiernos miren mas allá de sus fronteras económicas y geográficas al momento de activar sus políticas públicas, debido al hecho que cualquier crisis interna siempre va a trascender en los escenarios globalizados. Un caso típico es Grecia, cuya inminente quiebra jalaría a países, como España, Portugal, Italia, entre otros, que como se conoce, aun no se recuperan de la crisis hipotecaria, desatada en el 20082009.

En los escenarios globalizados, donde los espacios económicos están interconectados por mega redes informáticas, dándole mayores características de volatilidad, no hay espacios para irresponsabilidades en la gestión gubernamental. Hay que pensar que, quienes tienen por función conducir las riendas del Estado, no deben de licenciarse para implementar políticas cortoplacistas de corte populista y de supuestas bondades gubernamentales, ya que está demostrado que, quienes optan por esta forma de gobierno terminan por crear entornos de total turbulencia para aquellos agentes económicos que solo buscan agregar valor a la sociedad.

Va quedando evidenciando que la gestión gubernamental tiene muchos vicios $y$ debilidades, entre ellos el más preocupante es la corrupción, por ello, la hipótesis de que en vez de agregar valor a la sociedad entorpece el proceso de desarrollo quizás este cuasi demostrado, evidencia de ello, es que ahora se habla de una crisis soberana, cuya fuente de origen es justamente los deficientes sistemas de gobierno, cuyos conductores estratégicos, solo cuentan con objetivos pero no con visiones de largo plazo. Por ello, más que una restructuración económica es de imperiosa necesidad iniciar una reingeniería política pero de corte global, buscando convergencias en todos los espacios de gestión gubernamental, solo así se podría evitar emprender aquellas políticas tan nocivas para una sociedad como los llaman ahora "rescates financieros" de gobiernos o empresas en quiebras, que al final se traducen en desequilibrios fiscales, siendo el más claro ejemplo la economía norteamericana.

Se ha vuelto común escuchar, la "autoridad monetaria aplica un Plan de Rescate" para la banca o también un "gobierno ejecuta compra bonos" para ayudar a un gobierno que no cuenta con recursos ni siquiera para pagar planillas de la burocracia estatal o lo más recientes, los "gobiernos intervienen para estabilizar los mercados". Porque tendría que ocurrir estas injerencias gubernamentales totalmente dañinas para una sociedad? Si los mercados se movieran según sus propias leyes y reglas, pero bajo la atenta mirada de un gobierno responsable, serio y cauteloso, no tendría por qué ocurrir estos fenómenos atípicos, cuyas externalidades negativas terminan por debilitar las estructuras políticas y económicas del mundo global. 


\section{RATIOS FINANCIEROS PÚBLICOS QUE PROYECTAN DEFICIENTE GESTIÓN GUBERNAMENTAL}
a. Déficit fiscal/ PBI
b. Impuestos / PBI
c. Gasto público / PBI
d. Deuda pública/ PBI

Si un gobierno, aplica políticas fiscales expansivas bajo un marco debilitado de la presión tributaria, es de seguro que caerá en graves problemas financieros, el cual se reflejará en un elevado déficit fiscal. Pero ¿Por caer en este tipo de escenario de ingobernabilidad económica?: aquí algunas factores causales:

- Aumento de planilla del Estado

- Transferencias sociales (subsidios)

- Gastos de inversión publica

- Gastos en defensa

- Debilitamiento de la presión tributaria

- Evasión tributaria

- Elusión tributaria

- Informalidad económica ( actores económicos que no pagan impuestos)

Un gobierno que rompe la disciplina fiscal no mirará con atención la evolución de la recaudación tributaria, solo centrará su atención en la partida de gasto, en especial en aquellas partidas que puedan fortalecer su posición política, como son las transferencias sociales, los gastos en planillas improductivas, o lo que es peor, en malversaciones fiscales amparadas bajo un escudo legal. Este tipo de gestión, solo tiene un final, el cual será la aparición de desequilibrios presupuestales que serán asumidas más adelante por los que realmente tributan a favor del fisco. Pero quien origina este escenario? No es una empresa privada, este resultado obedece estrictamente a una deficiente gestión gubernamental, tal como han incurrido muchos países que ahora no encuentran salidas para salir del estancamiento económico.
Ejemplo de ellos son EE.UU. Italia, España, en este último país se ha creado una especie de "ejército de desempleados", el cual es la mejor evidencia de la deficiente gestión económica de los gobiernos, que actúan muchas veces bajo la complicidad de los grandes especuladores globales. Estos últimos, bajo la débil mirada de los gobiernos, si fueron los responsables directos de la crisis financiera global, y lo que es peor tuvieron como aliado a políticos que no dudaron en lanzarles salvavidas bajo el pretexto de resguardar el equilibrio de la economía global. Ahora simplemente tienen que pagar la factura por su posición " bondadosa".

Cuando los recursos tributarios no son suficientes para cubrir estas políticas expansivas de gasto público, es que nacen las deudas públicas, con ratios hasta de 2 por 1 , resultados que proyectan elevados riesgo financiero y que son considerados por los inversionistas globales como una clara señal para abandonar estos espacios turbulentos. Es más, como llevan sus cuentas fiscales a niveles de inmanejables, las calificadoras de riesgo como MOODYS o ESTÁNDAR \& POOOR simplmente le bajan de calificación crediticia, tal como lo ocurrido con la aún “primera economía del mundo" EE.UU. que remeció los mercados financieros globales.

Cuando sucede este fenómeno es que se habla de una crisis soberana, que origina la descalificación de todos los instrumentos financieros que puedan emitir los gobiernos metidos en este problema para equilibrar sus cuentas financieras. La transitividad de los efectos perniciosos de esta crisis hacia el sector real y monetario es directa e inmediata, apoyado por las redes que interconectan el mundo global.

Ya la han manifestado los representantes del FMI: “...Se viene una crisis global, quizás más fuerte de los que se observó en 
los años 2008 - 2009'”. A la luz de este comentario, es de imperiosa necesidad que los gobiernos ajusten sus políticas públicas y abandonen una vez por todas aquellas que solo generan huecos financieros de tipo gubernamental. Solo se exige "buen gobierno" para no caer en situaciones como ahora vienen atravesando las economías del primer mundo. Más claro, se tiene que profundizar la reformas estructurales, que conlleve a formar un Estado eficiente y que genere valor para la sociedad

El FMI en su Monitor Fiscal argumenta “...Pese a que muchos países han avanzado en la corrección de deficiencias fiscales fundamentales, el entorno fiscal mundial aún está sujeto a un alto grado de riesgo. En la zona del euro, muchos países han dado pasos significativos para reducir altos déficits y definir planes a mediano plazo, y se han comprometido a fortalecer las instituciones fiscales. Sin embargo, los diferenciales del costo de los préstamos han aumentado marcadamente en las economías más grandes, como Italia y España, lo cual es una indicación de que la actitud de los mercados puede variar de forma abrupta..." Es así como el FMI describe la grave situación financiera de los países desarrollados. Eso se llama crisis soberana ${ }^{2}$

\section{LA CRISIS SOBERANA EN CIFRAS: EVIDENCIA EMPÍRICA}

La indisciplina en el manejo de las cuentas fiscales está generando los efectos esperados, las cifras emitidas por el FMI en su último informe ${ }^{3}$, señala claramente que la economía global está entrando nuevamente en un peligroso terreno recesivo. Si bien los gene- radores de la crisis se encuentran en la zona del euro, pero esto no quita que los efectos se transmitan a las economías asiáticas y por ende, a esta parte de la Región, en especial aquellos países que están altamente conectados comercialmente y financieramente con los países en crisis.

Si se aprecia las cuentas fiscales de las principales economías del mundo, se puede apreciar lo mal que se ha estado manejando las cuentas fiscales. Países como Estados Unidos, considerando aun como la primera economía del mundo su ratio de deuda pública/PBI es en promedio el $100 \%$, siendo este resultado un pésimo escenario para la economía mundial, situación que se agrava cuando se observa que su déficit fiscal llega al 9.9\% de su PBI, que prácticamente se ha convertido en difícilmente manejable a los conductores de sus políticas publicas. Este caso conllevó que Standar \& Poor's le baje su calificación del crédito de "AAA" a "AA+", que retumbo los mercados financieros globales.

Este mismo escenario se calca para los países europeos, que contagiados por la crisis Griega, y su deficiente gestión pública, el cual se plasma en el elevado déficit fiscal y deuda pública, tal como lo es en Italia, Francia, pero con mas gravedad España, pintan un escenario de total debilidad a la economía global. Este último país por cierto es uno de los más afectados, cuya crisis lo ha convertido en la economía con la mayor cantidad de desempleo abierto en toda Europa y siendo las más vulnerable a las turbulencia de los mercados globales. Su déficit fiscal y ratio deuda pública, los cuales llegan al 10,5\% y $67.5 \%$, representan una mezcla de resulta-

FMI: perspectivas de las Américas. Setiembre del 2011.

FMI. Monitor fiscal : 2011

FMI: Informe sobre las perspectivas de la economía mundial. Setiembre 2011. 
dos que volatilizan su frente interno, que han generado graves focos sociales de conflicto, situación que era atípico en este tipo de economías.

Finanzas.com señala de la forma siguiente este hecho global “ ... La agencia de medición de riesgos Moody's rebajó ( $05 / 10 / 11$ ) hoy la calificación de la deuda soberana de Italia en tres escalones, desde Aa2 hasta A2, con perspectiva negativa, una revisión a la baja que atribuyó a los elevados niveles de deuda pública del país. La decisión de Moody's tendrá consecuencias, pues la agencia ha advertido de que habrá más rebajas para el resto de países que tengan una nota por debajo de la triple 'A' “Si esta Agencia le pone esta calificación a Italia, es por su economía está debilitada estructuralmente y que ya sería parte de ese eslabón de crisis global. La detonante como se vuelve a recalcar es el deterioro de las cuentas fiscales. El hecho de que Moody's señale que la rebaja de calificación crediticia a Italia está motivada por el creciente peligro sobre el crecimiento económico del país debido a sus "debilidades estructurales" y a las pésimas perspectivas de crecimiento a nivel global, debe llenar de alarma a una Zona económica no sabe como estructurar murallas de contención a los efectos de la crisis soberana. La prewgunta es ¿ cómo saldrá de la crisis este economía cuyo ratio deuda pública/PBI llega en promedio al 120\%?. Quién le comprará los bonos soberanos que emita? Es importante que el FMI $y$ otra entidades financieras globales como el Banco Central Europeo (BCE), tomen posiciones más duras y no entren al mercado de capitales a comprar deudas de dudoso cumplimiento, estas acciones solo son paliativos artificiales que hasta ahora no han dado ningún tipo de solución estructura. Es importante que la economía se auto regule, asi como lo hace todo mercado, o en todo caso que los mismos gobiernos aprendan se sus errores, que ponen en peligro la estabilidad de la economía mundial.

El desequilibrio fiscal, ha trastocado otros espacios financieros, como el mercado de capitales de tipo global, donde se negocian los bonos soberanos, los cuales son emitidos justamente por los gobiernos para financiar los resultados negativos de las cuentas fiscales, que dicho sea de paso se han llegado a depreciar en estos mercados. Ahora por ejemplo ya no se podría conceptualizar al tipo de interés que paga los bonos de la Reserva Federal de Estados Unidos como la tasa sin riesgo, en base al hecho que a este país le hayan bajado la calificación crediticia, ya no se puede asegurar que su grado de incumplimiento de deudas contraídas sea igual a cero. Hay que recordar que, cuando un inversionista global planeaba realizar inversiones tomaba esta tasa como referencia para evaluar sus retornos por inversión, adicionándole una prima compensatoria por el riesgo asumido, pero bajo actuales coyunturas estas formulas financieras exigirían una revisión conceptual, con el propósito de diseñar nuevos modelos, donde se explicite una nueva tasa de referencia global. Es otro de resultados de la crisis soberana global.

Los modelos teóricos argumentan que, si los gobiernos aplican políticas expansivas de gasto público, el PBI, vía demanda agregada debe tener el mismo comportamiento, pero ¿Por qué en los países en crisis no se experimenta este resultado?, aquí hay que poner bajo juicio valorativo la variable confianza; bajo esta óptica, se puede argumentar que el sector empresarial como el ciudadano común y corriente, como principales actores de los movimientos económicos, han dejado de confiar en las políticas gubernamentales, es por ello que los efectos multiplicadores de las practicas intervencionistas de los go- 
biernos solo tienen mínimos impactos en la economía, con la consecuente profundización de la recesión. En la última crisis financiera global, la intervención de los gobiernos fue inmediata, esta se operativizo a través de operaciones de salvatajes de bancos o grandes empresas corporativas en estado total de insolvencia, pero a pesar de estas medidas, no se siente reactivaciones importantes en la actividad productiva, todo lo contrario, el FMI en su último informe ha tomado posiciones más cautelosas sobre los crecimientos esperados de estos países. A la crisis financiera fiscal ahora hay que agregarle la recesión y la caídas bursátiles, síntomas de la cadena perniciosa de la crisis soberana.

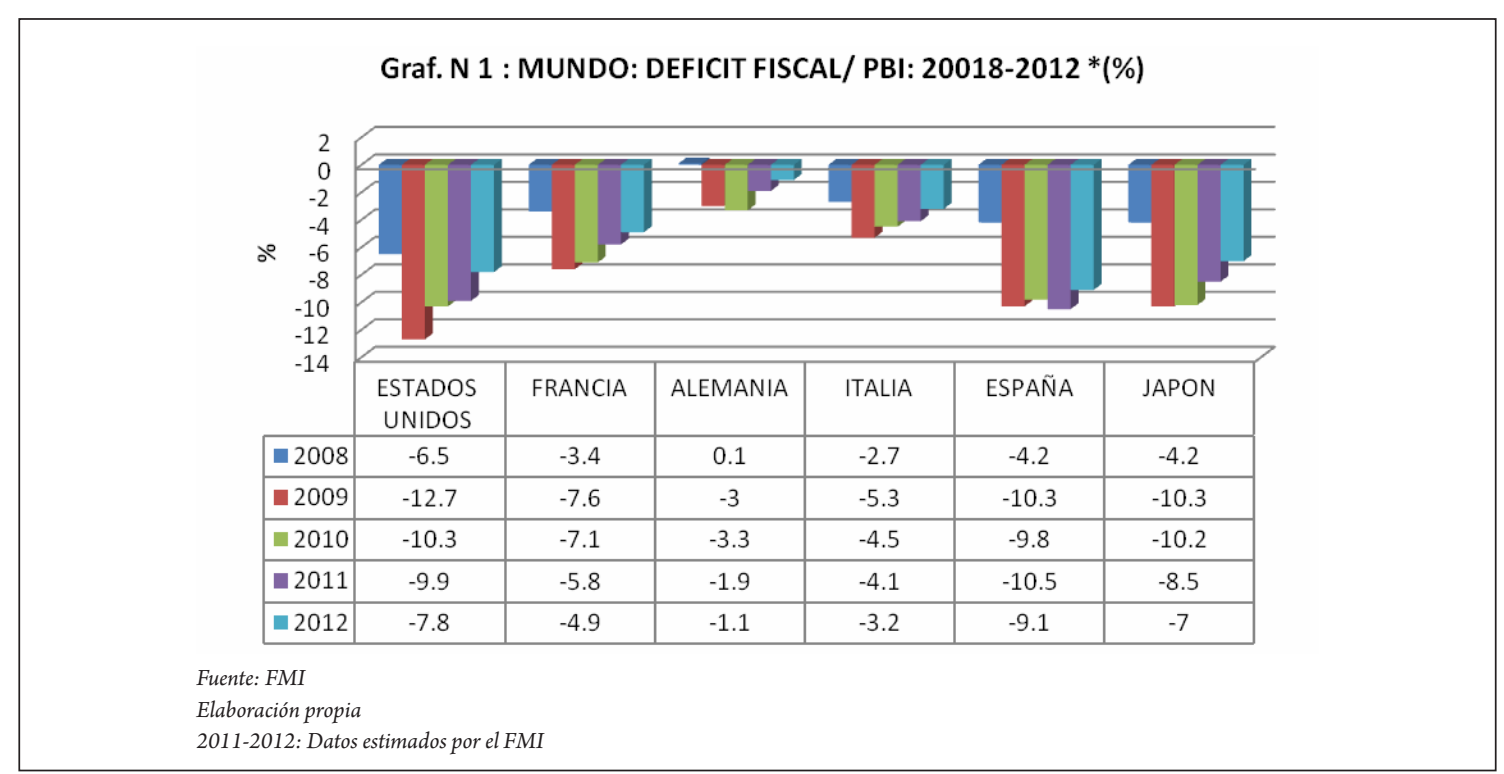

No hay simetría entre las cuentas fiscales y reales, mientras que el déficit fiscal se eleva conjuntamente con la deuda pública, por otro lado los ajustes del PBI van para abajo. Tal como se aprecia en el grafico N 2 , la zona del euro y Estados Unidos, su PBI no logra alcanzar cifras expectantes para superar sus problemas de desempleo. La cuasi quiebra es inminente, a no ser que los ajustes reales y financieros sean de tipo estructural y no simples programas de salvatajes a través de compras de deudas soberanas.

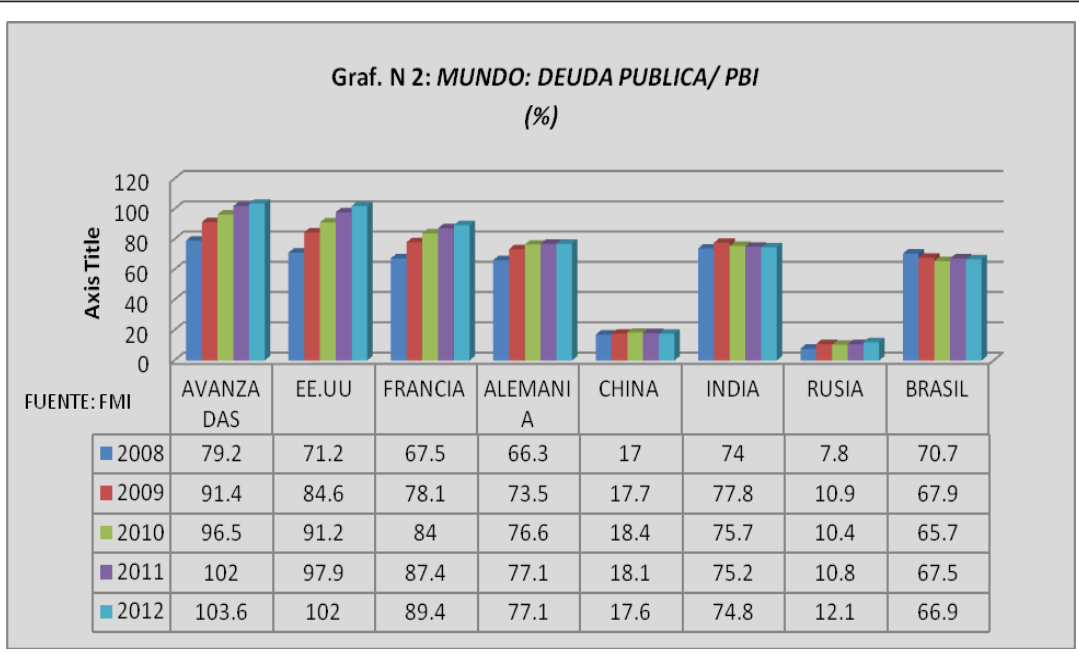




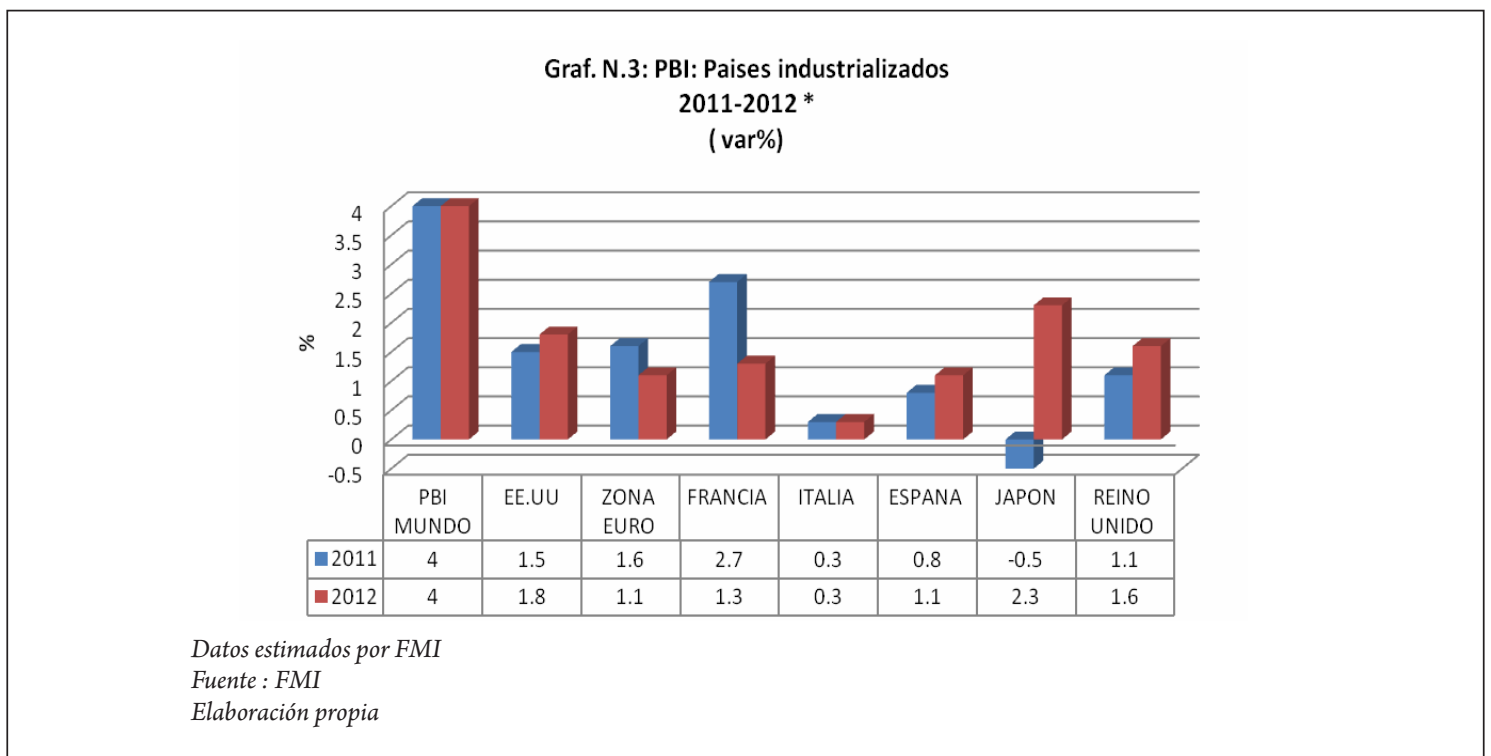

La hipótesis de que la disciplina económica al final se convierte en excelentes fundamentos para un crecimiento sostenido cobra fuerza con los resultados que se observan en los países asiáticos, que según el FMI, también experimentaran un retroceso, pero la senda de su desarrollo a largo plazo se mantiene con la fortalezas necesarias para alcanzar cifras del $7 \%$ u $8 \%$ de crecimiento real. El caso emblemático es China , cuyo déficit fiscal comparado con los demás países industrializados denotan coherencia y responsabilidad en el manejo de sus cuentas fiscales, es por ello que esta economía proyecta a convertirse en la hegemónica del mundo, ya no en el largo plazo como todos estimaban, sino en el plazo más corto posible, gracias al diseño y ejecución de sus políticas públicas con alto contenido visionario, donde se aprecia una elevada ponderación al crecimiento de su aparato exportador.

Lograr un déficit fiscal del $1.6 \%$ y $0.7 \%$ con una tasa de crecimiento del PBI del 9.5\%, como lo proyecta alcanzar China ( cuadro N04), es mucho más que meritorio para este país, escenario que se fortalece cuando se visualiza que este proceso de crecimiento lo hace con una deuda pública altanamente manejable. Su riesgo comparado con otras economías de la zona del euro es mínimo, es por ello que este país, con otros asiáticos, se constituirá en el nuevo eje de dominio económico global. Este resultado, solo se consigue con coherencia y disciplina fiscal.

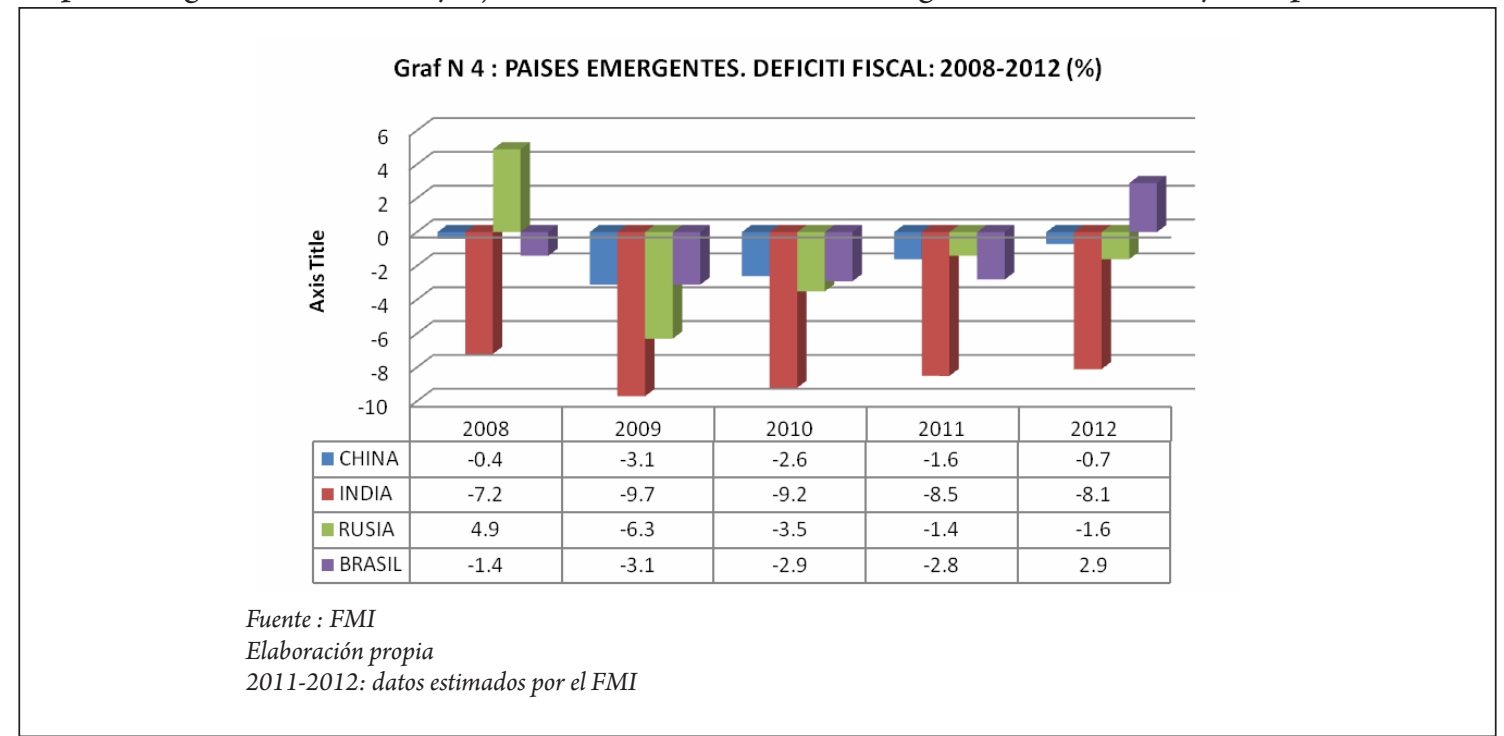


No solo China tiene prudencia en el resultado de sus cuentas fiscales, sino también hay otros países emergentes con esa característica, entre ellos está el Perú, que en estos últimos 20 años ha logrado entender que la disciplina fiscal es uno de los pilares para sustentar un crecimiento sano y sostenido, si bien este país es pequeño en el orbe económico mundial, pero viene emitiendo continuamente señales de responsabilidad en su finanzas publicas, en base a ello es que el resultado del déficit fiscal no sobrepasa el $1.5 \%{ }^{4} \mathrm{y}$ se proyecta alcanzar cifras positivas para el año 2012, este resultado se puede resaltar mas , sabiendo que la presión tributaria es una de las más bajas de la región, que en promedio bordea el $15 \%$.

Bajo el mercado globalizado, no se puede hablar de blindajes económicos. La interconexión de los mercados si bien podría generar grandes beneficios, vía las transacciones comerciales y financieras, pero también se puede convertir en el detonante para el desmoramiento en serie de los países afectados con este mega problema global. El PERU, como integrante de la Región, no puede estar al margen de esta crisis, a sabiendas que es un país que sustenta su crecimiento económico en las exportaciones primarias o de commodities, bajo este marco de análisis, se puede afirmar que, aun sigue enclavada en la teoría clásicas del comercio internacional como la Ricardiana, por ello que su supremacía económica lo encontramos en los sectores que generan mínimo valor agregado.
Si bien los impactos de la crisis soberana en la Región aun son marginales, hecho que fundamenta la posición optimista del FMI hacia las economías que la conforman, pero esto no quita que los gobiernos se exijan en diseñar políticas para enfrentar con éxitos los valatilidades globales que se avecinan, una de ellas y diríamos la más relevante es la mantención de las cuentas fiscales totalmente equilibradas y en azul, solo así los riesgos soberanos serán mínimos y los Bonos que puedan emitir para conseguir financiamiento de largo plazo tendrán la mejor calificación del mercado crediticio global.

El FMI ha calificado así a esta parte de la Región: "En este entorno, América Latina y el Caribe deberían, en general, mantener el rumbo actual de sus políticas económicas y seguir recomponiendo los márgenes necesarios para la aplicación de políticas anti cíclicas en el futuro, pero también deberían estar preparados para modificar sus políticas si los vientos mundiales cambian de dirección." A la luz de este análisis se puede afirmar que Perú va por un buen camino, pero necesita reforzar su escenario interno con políticas que inyecten más confianza a los inversionistas globales.

Las cifras para el Perú son alentadoras, un PBI en crecimiento sostenido, salvo el 2009, que fue producto de la crisis financiera global, complementado por unas cuentas fiscales que señalan estabilidad fiscal. ( Ver Graf. No 5) El camino es correcto, pero no reflejan una dosis de inmunidad ante la crisis global de tipo soberano.

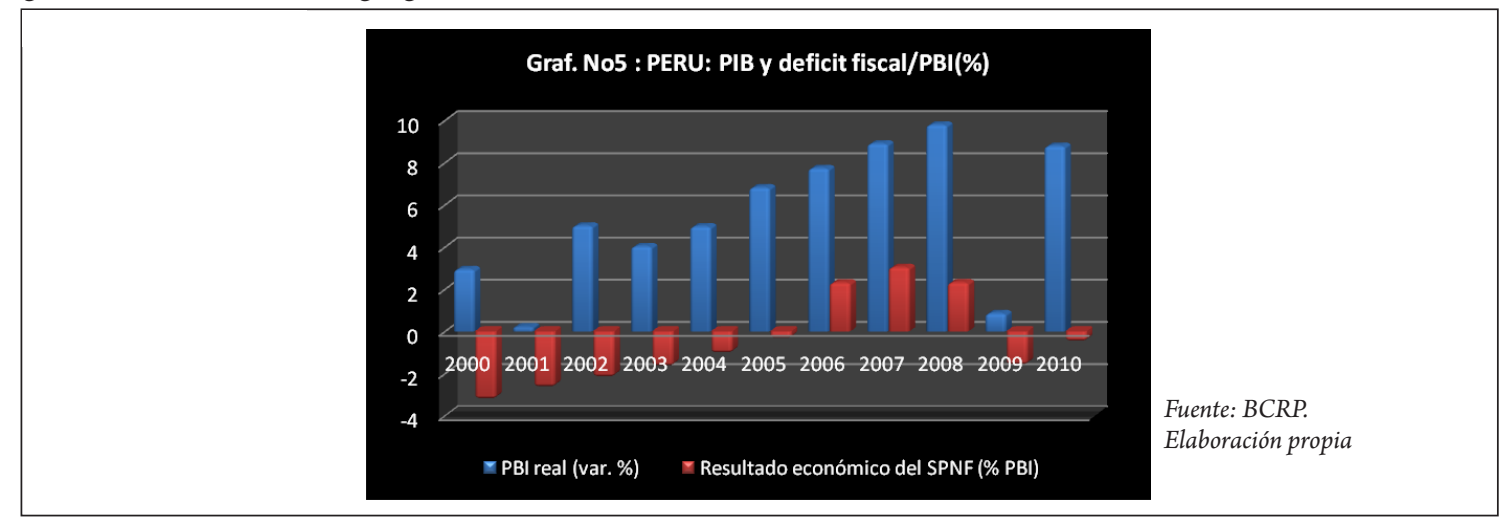

MEF: Marco Macroeconómico Multianual: 2011-2013

FMI. Perspectivas económicas de las Américas. Actualizado a setiembre del 2011 


\section{¿ QUÉ HACER PARA NO CAER EN ESCENARIOS DE CRISIS FISCAL?}

1. Diseñar e implementar políticas fiscales contraciclicas. Aumentar los gastos públicos cuando el escenario económico lo amerite. Dejar la responsabilidad de inversión al sector privado

2. Los gastos públicos deben priorizar las inversiones y que tengan un elevado retorno social. Estas inversiones deben realizarse en función de cuanto sea la recaudación tributaria.

3. Evitar caer en elevados ratios de deuda pública /PBI. Los gastos internos deben de sustentarse en los ingresos tributarios y no tributarios.

4. Para que los gobiernos fundamentan sus políticas expansivas de gasto, la recaudación tributaria debe tener el mismo comportamiento, de esta forma se evitará caer en emisiones de deuda pública

5. Profundizar las acciones de fiscalización a fin de que se fortalezca los ingresos tributarios. Se debe de eliminar todo tipo de exoneraciones tributarias y subsidios improductivos para la sociedad.

6. Emitir bonos soberanos, cuando sea necesarios financiar gastos de inversión, pero aquellas que solo sean rentables, no para cubrir gastos corrientes. Los gastos de inversión deben ser debidamente priorizados en función de las necesidades de la población y de la rentabilidad de cada proyecto.

7. Desterrar dentro de la política fiscal, acciones de salvataje con fondos públicos a empresas privadas que tengan problemas de quiebra.

8. Las políticas sociales de inclusión solo deben de ejecutarse si es que el gobierno cuenta con los recursos financiero suficientes paras estos tipos de programas.
Solo se puede recurrir a fuentes externas, cuando los desembolsos no sean reembolsables.

Si los gobiernos aplican las medidas sugeridas, de seguro que aumentarán sus fortalezas internas y evitarán caer en crisis soberana, que como ya mencionó ahora ha desatado una nueva espiral de crisis global.

\section{CONCLUSIONES}

1. Las economías de la zona del euro presentan serios desequilibrios en sus cuentas fiscales, específicamente en el déficit fiscal y de deuda pública, lo cual ha generado que estos países, tengan problemas de crisis soberana.

2. Esta misma situación se presenta en la economía norteamericana, cuya indisciplina fiscal le ha costado la rebaja de su calificación crediticia y apunta a tener severos problemas macroeconómicos y políticos de carácter interno.

3. El escenario de crisis soberana se ha agravado con la estimación del PBI de las principales economías del mundo, cuya tendencia es al decrecimiento, en especial EE.UU, cuyo revés económico representaría un serio peligro para las economías emergentes.

4. Las economías emergentes muestran indicadores sólidos de gestión fiscal, especialmente los países asiáticos, que son los principales socios comerciales de Perú, pero al crisis soberana afectará su posición de crecimiento sostenido, pero sin poner en riesgo sus fortalezas económicas y políticas de tipo estructural.

5. Sin bien las economías emergentes han desarrollado fortalezas internas y externas, entre ellos el Perú, pero esto no implica que se encuentren inmune a la espiral de la crisis soberana global. 
6. El Perú muestra sólidos indicadores fiscales, y un PBI en crecimiento, por ello las políticas públicas se podría calificar como las más apropiadas para sostener este escenario. Este tipo de gestión fiscal tiene que seguir mostrando señales de disciplina para atraer las inversiones globales, que en Europa ya no encuentran el escenario propicio para lograr retornos sostenidos y con bajos niveles de riesgo.

\section{REFRENCIAS BIBLIOGRÁFICAS}

1. Fondo Monetario Internacional (FMI) : Informe sobre la estabilidad financiera mundial" - setiembre 2011.

2. Fondo Monetario Internacional (FMI) : "Perspectivas de la economía Mundial" - setiembre 2011.

3. Fondo Monetario Internacional (FMI) : "monitor fiscal" - setiembre 2011.

4. Fondo Monetario Internacional (FMI) : "Perspectivas económicas: las Américas" setiembre 2011. 